\section{Occupational Mortality}

The Registrar General's reports on occupational mortality are laborious and time-consuming undertakings and usually appear several years after the census of populations on which they are based has been taken. The last report from the 1931 census was published in 1938 . The calculation of death rates in relation to the 1951 census is being made for a five-year period (1949 to 1953) instead of the usual three years, and the report cannot be expected before 1958.

Using the death rates in 1950 the Registrar General for England and Wales (1954) has calculated comparative mortality rates in the main social classes and in a few large occupational groups. While these figures will not be as reliable as those in the full reports, they go some way to fill the gap in occupational mortality data during the past 20 years. Those with experience of certain occupations or diseases have been invited to contribute commentaries on the data contained in this latest report. The first two contributions follow.

\section{Cancer of the Respiratory Tract RICHARD DOLL}

In the 20 years that have elapsed between the last two censuses the mortality from lung cancer has increased sixfold and it is, therefore, of particular interest to see whether there has been any change in the social distribution of the disease to accord with the distribution of any of the factors which may be responsible for the increase. In the period 1930-32 the mortality from lung cancer varied little from one social class to another and there was no indication of a gradient in either direction with descent in the social scale. It appears now that among men aged 20-64 the disease may be less common in the wealthiest classes (standardized mortality ratio for Class I, 80, for Class V, 116). This tendency, however, is not evident for older men or for women of either age group.

None of the occupational groups specified by the Registrar General in the present limited statistics shows a grossly high mortality - the highest being men in the Armed Forces aged 20-64 with a standardized mortality ratio of 150 , but, as previously, consistently low mortalities at all ages are recorded for farmers, agricultural workers, and mineworkers, and for the wives of men in all three groups. When these special groups are removed the upward gradient in mortality with descent in the social scale for men aged 20-64 years becomes much more definite :

*Registrar General's Decennial Supplement England and Wales
(1951). Occupational Mortality, Part 1. H.M. Stationery Office, (1951). Occupational Mortality, Part 1. H.M. Stationery Office,
London.

\begin{tabular}{lr|c|c|c|c|c}
\hline & \multicolumn{5}{|c}{ S.M.R. in Social Class } \\
\cline { 2 - 7 } & I & II & III & IV & V \\
\hline Men aged 20-64 years &.. & 80 & 79 & 108 & 89 & 116 \\
$\begin{array}{l}\text { Men aged 20-64 years, less } \\
\text { farmers, agricultural workers, }\end{array}$ & & & & & \\
and mineworkers .. &.. & 80 & 85 & 109 & 107 & 116 \\
\hline
\end{tabular}

Were a similar gradient found among older men and among married women it might be possible to attribute this finding to an effect of atmospheric pollution, since it is not unreasonable to believe that more of the men in the poorer social classes tend to live in the more polluted areas. The facts are, however, otherwise, and indeed the highest standardized mortality ratio among married women is found in social class $\mathbf{I}$.

\begin{tabular}{|c|c|c|c|c|c|}
\hline & \multicolumn{5}{|c|}{$\begin{array}{l}\text { S.M.R. (or Proportionate } \\
\text { Mortality Ratio) for Persons } \\
\text { over } 65 \text { in Social Class }\end{array}$} \\
\hline & $\mathbf{I}$ & II & III & IV & $\mathbf{V}$ \\
\hline Men aged 65 years and above* & 108 & 102 & 109 & 106 & 118 \\
\hline $\begin{array}{rrrr}\text { Married women } & \text { aged } & 20-64 \\
\text { years } \dagger & \ldots & . & .\end{array}$ & $120_{\ddagger}^{\ddagger}$ & 99 & 106 & 116 & 91 \\
\hline $\begin{array}{c}\text { Married women aged } 65 \text { years } \\
\text { and above } \dagger \ldots \\
\end{array}$ & 176 & 110 & 101 & 111 & 103 \\
\hline
\end{tabular}

*Less farmers, agricultural workers, and mineworkers.

t Less wives of farmers, agricultural workers, and mineworkers.

$\ddagger$ Ratios in italics based on fewer than 50 deaths.

Differences in cigarette consumption could account for the high mortality among the wealthier women who may well have begun smoking a decade or more earlier than the average, but whether they can account for the increasing mortality with descent in the social scale among men under 65 years and for the low mortality among farmers, agricultural workers, mineworkers, and their wives is unknown. Such a factor would, one suspects, accord well with the high mortality from lung cancer which occurred in the Armed Forces.

The consistent findings of a low mortality for mineworkers (S.M.R. for mineworkers aged 20-64 years in Class III, 92 ; in Class IV, 55. Proportionate ratio aged 65 years + in Class III, 61 ; in Class IV, 56) once again confirms the lack of association between lung cancer and exposure to dust per se.

Cancer of the larynx has, in the past, provided a good example of a type of cancer which was closely dependent on social conditions. The increasing gradient with descent in the social scale revealed in 1921-23 is, however, now no longer apparent. This may, perhaps, reflect social changes in the consumption of alcohol. The present report does not give figures for workers in the alcoholic trades and it is not certain that the previously observed association with alcohol persists.

\section{Transport Workers \\ L. G. NORMAN}

The 1951 Supplement differs in a number of respects from those previously published. There are marginal differences due to revisions in the Classification of 